\title{
Cullen e a introdução do termo "neurose" na medicina
}

Mário Eduardo Costa Pereira

O termo médico "neuroses" começa a ser empregado de forma técnica a partir de 1769, ano em que é publicada a primeira edição da célebre Synopsis Nosologiae Methodicae do médico escocês William Cullen (1710-1790). Tratava-se então, segundo um ordenamento classificatório inspirado na taxonomia de Lineu, da designação de uma classe de afecções gerais do sistema nervoso, não acompanhadas de febre e atingindo de forma privilegiada a sensibilidade e o movimento, reunindo quatro "ordens" específicas de fenômenos: os comas, as adinamias; as afecções espasmódicas sem febre e as vesânias, como a mania (loucura) e a melancolia

Palavras-chave: Neuroses, psicose, Cullen, taxonomia 
Em uma recente edição da renomada revista History of Psychiatry, Køppe (2009) observa que o tema das origens históricas do conceito de neurose raramente tem sido tratado pelos pesquisadores do campo da psicopatologia. De fato, embora existam inúmeros estudos sobre a história da constituição teórica de diferentes neuroses específicas, muito poucos se debruçaram sobre a categoria "neurose" enquanto tal. Køppe reconhece apenas dois trabalhos realmente substanciais sobre essa questão: o livro do espanhol José Lopes Pienero, Historical origins of the concept of neurosis, publicado em 1983 pela Cambridge University Press e a tese de doutorado do pesquisador alemão J. S. Maier, apresentada em 1948 e intitulada Beitrag zur Geschichte des Neurosebegriffes von 1778-1887 (Contribuição para uma história do conceito de neurose de 1778-1887). Esse fato causa estranheza, segundo Køppe, pois o termo neurose e a distinção clássica entre "neurose" e "psicose" constituem algumas das referências mais utilizadas e conhecidas no campo psiquiátrico.

A versão canônica, mas surpreendentemente reduzida, da história da concepção médica da neurose situa a origem técnica desse termo no ano de 1769 , quando é publicada a primeira edição da célebre Synopsis Nosologiae Methodicae do médico escocês William Cullen (1710-1790). Em seus tratados nosográficos sub- 
sequentes, a designação "neurose" abrange mais ou menos o mesmo âmbito semântico em relação ao qual fora inicialmente descrita.

$\mathrm{Na}$ verdade, Cullen emprega esse termo principalmente no plural - "neuroses" -, uma vez que este se referia a uma "classe" de doenças e não a uma "espécie" nosológica em particular. O elemento comum permitindo a reunião de patologias muito diversas, como veremos, sob a égide da designação proposta pelo médico escocês é o fato de estas se manifestarem como afecções gerais do sistema nervoso, não acompanhadas de febre e atingindo de forma privilegiada a sensibilidade e o movimento. Tratavam-se, portanto, de enfermidades nervosas não decorrentes de lesão localizada ou de patologia febril.

Assim, aos olhos da psicopatologia contemporânea, em sua versão original, a noção de "neuroses" recobria um campo bastante heterogêneo de afecções, organizadas a partir de quatro "ordens" específicas: 1) os comas (ou perda dos movimentos voluntários, como na apoplexia); 2) as adinamias (doenças constituídas pelo enfraquecimento ou perda dos movimentos nas funções vitais ou naturais, incluindo assim a síncope, a dispepsia e a hipocondria); 3 ) as afecções espasmódicas sem febre, como o tétano, a epilepsia, a asma e a histeria e 4) as vesânias, como a mania (loucura) e a melancolia.

Vemos que em sua forma inicial, as neuroses não abrangiam o campo referencial que designam atualmente, uma vez que não apenas incluíam transtornos de fundamento claramente biológico, como também os fenômenos psicóticos. Tal concepção nosográfica proposta por Cullen exerce grande influência no pensamento médico das décadas subsequentes, mesmo no contexto europeu continental onde observamos Charcot designar - quase um século mais tarde - histeria e epilepsia como sendo "as duas grandes neuroses" e Ballet incluir o Mal de Parkinson, as manifestações coreicas e também a epilepsia como manifestações neuróticas. Em larga medida, os estudos de Charcot sobre a histeria constituíram um esforço para demonstrar o caráter "neurótico", no sentido de Cullen, dessa enigmática patologia, tentando fazer dela "uma doença como as outras" (cf. Pereira, 1999).

O caráter de estranheza provocado no leitor dos tempos de hoje pelo sistema proposto na Synopsis Nosologiae Methodicae, de 1769, assim como nas First Lines in the Practice of Physic (1785), decorre da aplicação estrita por Cullen no campo médico do método taxonômico elaborado por Lineu para classificar os fenômenos da natureza. É assim, pois, que vemos as diferentes entidades nosológicas concebidas como "espécies" naturais agrupadas em "ordens" e estas, por sua vez, reunidas em "classes". Bastante ilustrativo desse procedimento teórico- 
metodológico é o título completo de sua Synopsis: Nosologia ou ordenamento sistemático das enfermidades nas classes, ordens, gêneros e espécies; com os caracteres distintivos de cada descrição dos sistemas de Sauvages, Linneo, Vogel, Sagar e McBride.

Foi apenas progressivamente que a concepção contemporânea de "neurose" foi se constituindo e difundindo universalmente. Assim, já na obra de Pinel, o termo de "névrose" é introduzido para designar as doenças do sistema nervoso sem base orgânica conhecida. Em 1845, o médico alemão Ernst Feuchtersleben (18061849) propõe a denominação de "psicose" para os transtornos mentais decorrentes da interação mórbida do psíquico sobre o físico, ou seja, em uma acepção que não contém ainda a referência a uma ruptura radical do sujeito com as formas socialmente compartilhadas de organização da realidade e da experiência do eu próprio.

Serão os trabalhos de Janet, Breuer e, sobretudo, de Freud sobre a histeria que trarão para a tradição psicopatológica a conotação forte de perturbação psicológica, comportando diferentes níveis de sofrimento psíquico, com manutenção do julgamento de realidade e integridade da vivência do eu. A obra freudiana insistirá quanto à importância do conflito psíquico inconsciente e da dimensão simbólica dos sintomas, permitindo ao sujeito uma realização disfarçada de um desejo incompatível com o restante das representações mentais que esse tem de si mesmo.

Na psiquiatria contemporânea, o termo "neurose" é cada vez menos empregado em sua forma substantiva nos sistemas diagnósticos atuais, embora a Classificação Internacional de Doenças em sua $10^{a}$ Edição (CID 10), ainda mantenha, sob forma de adjetivo, a categoria de "transtornos neuróticos".

\section{Referências}

EDDy, M.D. The medium of signs: nominalism, language and the philosophy of mind in the early thought of Dugald Stewart. Studies in History and Philosophy of Science Part C: Studies in History and Philosophy of Biological and Biomedical Sciences, v. 37, Issue 3, p. 373-393, september 2006.

KøPPE, S. Neurosis: aspects of its conceptual development in the nineteenth century. History of Psychiatry, n. 20, p. 27-46, 2009. 
MAIER, J.S. Beitrag zur Geschichte des Neurosebegriffes von 1778-1887. Tese de Doutorado, University of Erlangen, 1948.

Pereira, M.E.C. C'est toujours la même chose: Charcot e a descrição do Grande Ataque Histérico. Revista Latinoamericana de Psicopatologia Fundamental, São Paulo, v. II, n. 3, p. 159-165, set. 1999.

Pienero, J.M. Lopez. Historical origin of the concept of neuroses. Cambridge: Cambridge University Press, 1983.

SAURI, J. A construção do conceito de neurose (I). Os vapores e os nervos. Revista Latinoamericana Psicopatologia Fundamental, São Paulo, v. VIII, n. 1, p. 73-85, jan. 2005.

A construção do conceito de neurose (II). Nosologia e neurose. Revista Latinoamericana Psicopatologia Fundamental, São Paulo, v. VIII, n. 2, p. 289-302, jun. 2005.

\section{Resumos}

(Cullen y la introducción del término "neurosis" en la medicina)

El termino médico “neurosis"comienza a ser empleado de forma técnica a partir de 1769, año en que es publicada la primera edición de la célebre Synopsis Nosologiae Methodicae del médico escocés William Cullen (1710-1790). Se trataba ahí, según un ordenamiento clasificatorio inspirado en la taxonomía de Lineu, de la designación de una clase de afecciones generales del sistema nervioso, no acompañadas de fiebre y alcanzando de forma privilegiada la sensibilidad y el movimiento, reuniendo cuatro “ordenes" específicas de fenómenos: los comas, las adinamias; las afecciones espasmódicas sin fiebre y las vesanias, como la manía (locura) y la melancolía.

Palabras claves: Neurosis, psicosis, Cullen, taxonomía

(Cullen et l'introduction du terme "névrose" en médecine)

Le terme médical "névroses" commence à être employé de façon technique dès 1769, avec la publication de la première édition de la célèbre Synopsis Nosologiae Methodicae du médecin écossais William Cullen (1710-1790). Fondée sur la démarche taxonomique proposée par Carl von Linée, cette notion désignait une classe de troubles généraux du système nerveux sans présence concomitante de fièvre qui atteignaient de 
façon privilégié la sensibilité et les mouvements. Cette notion réunissait alors quatre "ordres" différents de phénomènes: les comas, les adynamies; les troubles spasmodiques sans fièvre, ainsi que les vésanies, comme la manie (folie) et la mélancolie.

Mots-clés: Névroses, psychose, Cullen, taxonomie

(Cullen and the earliest use of the term "neurosis" in medicine)

The term "neurosis" in its technical, or medical, sense, was coined in 1769 with the publication of the first edition of the famous Synopsis Nosologiae Methodicae, by the Scottish physician William Cullen (1710-1790). According to a classification based on Linnaeus's taxonomy, the concept refers to a class of general affections of the nervous system that are not accompanied by fever and that especially affect sensitivity and movement. The category consists of four specific "orders" of phenomena: comas, adynamias, spasmodic affections without fever, and vesanias, such as manias (madness), and melancholia.

Key words: Neuroses; psychosis, Cullen, taxonomy

Citação/Citation: Pereira, M.E.C. Cullen e a introdução do termo "neurose" na medicina. Revista Latinoamericana de Psicopatologia Fundamental, São Paulo, v. 13, n.1, p. 128134, mar. 2010.

Editor do artigo/Editor: Prof. Dr. Mario Eduardo Costa Pereira

Recebido/Received: 10.2.2010/2.10.2010 Aceito/Accepted: 18.2.2010/2.18.2010

Copyright: () 2010 Associação Universitária de Pesquisa em Psicopatologia Fundamental/University Association for Research in Fundamental Psychopathology. Este é um artigo de livre acesso, que permite uso irrestrito, distribuição re reprodução em qualquer meio, desde que o autor e a fonte sejam citados/ This is an open-acess article, which permits unrestricted use, distribution, and reproduction in any madium, provided the original author and source are credited.

Financiamento: $\mathrm{O}$ autor declara não ter sido financiado ou apoiado/ The author has no support of funding to report.

Conflito de interesses: O autor declara que não há conflito de interesse/ The author declares that has no conflict of interest 


\section{Mario Eduardo Costa Pereira}

Psiquiatra; psicanalista; professor titular de Psicopatologia Clínica do Laboratoire de Psychopathologie Clinique et Psychanalyse da Universidade de Provence/Aix-Marseille (Marseille, França); doutor em Psicopatologia Fundamental e Psicanálise pela Universidade Paris 7 (Paris, França); membro da Associação Universitária de Pesquisas em Psicopatologia Fundamental (São Paulo, SP, Brasil); autor dos livros Pânico e desamparo (São Paulo: Escuta, 1999) e Psicopatologia dos ataques de pânico (São Paulo: Escuta, 2003).

Laboratoire de Psychanalyse et Psychopathologie Clinique Université de Provence

Centre Saint-Charles

Case 37

3, place Victor Hugo

13331 Marseille cedex 3 France

e-mail: marioecpereira@uol.com.br 